\title{
Tribute
}

\section{A Tribute to Late Professor Tamal Kumar Biswas}

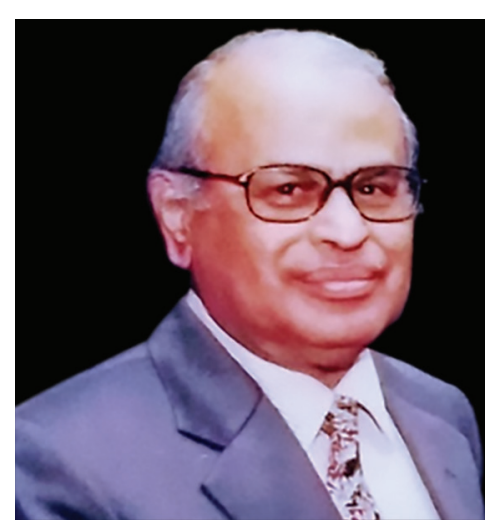

Late Prof. Tamal Kumar Biswas (1938-2018)

Professor Tamal Kumar Biswas, who passed away recently at the age of eighty, left an irreparable vacuity in the field of medicine. For long he will be missed by his family members, friends, patients, and colleagues-past and present - for being a human being par excellence whose adherence to values, ethics, and humanism was beyond question. In his death, Professor Biswas has left a legacy which will be a challenge for his posterity to meet and match. His way of treating his patients was unique. He was a keen listener, and he heeded carefully to the problems of his patients and diagnosed their maladies with extreme precision and accuracy.

Youngest of the five sons of Rohini Kumar Biswas, Professor Biswas was born in 1938 in the village of Borogram, Maymansingh district, now in Bangladesh. His early schooling was at Padmapukur Institute, Kolkata. He completed I.Sc from Surendranath College, Kolkata and joined Calcutta National Medical College as a medical student in 1956 graduating in 1961. Subsequently, he obtained his Doctor of Medicine degree from Calcutta University. He joined Calcutta National Medical College as a faculty member in the Department of Medicine in 1978.

In the course of time, Professor Biswas became head of the same department and retired in 1998, working for more than two decades in the same institute. After his formal retirement, he joined as a consultant in reputable hospitals of Kolkata including Calcutta Medical Research Institute (CMRI), Kothari Medical Centre, Ruby General Hospital, Rabindranath Tagore Hospital till 2012.

As a teacher, Professor Biswas was inspirational and was student-friendly. His students are now found across the world engaged in the restoration of health and keeping mankind free from maladies. They certainly owe their success to him.

Recipient of numerous awards for his outstanding contributions both in the medical academy and practice, Professor Biswas was awarded the prestigious Bidhan Chandra Roy Award (Dr B. C. Roy Award, 2018) which is the highest honor in medical science of our country.

His name in the history of API will never be forgotten. API WB Chapter will remember his contributions for generations to come. He served API West Bengal Chapter in various capabilities. He was Honorary Secretary of the chapter during 1988 to 1990 and Chairman from 1996 to 1998. He was the Organizing Secretary of APICON 1999 in Kolkata.

Survived by his wife and two worthy sons, he breathed his last on 10th November 2018. His elder son belongs to the medical fraternity, and the younger one is an engineer.

His ever smiling face and charming behavior will remain in our memory as a beacon light forever. May almighty grant the departed soul eternal peace and tranquility! Professor Biswas may not be amongst us but his memories will remain etched in our minds forever.

Acknowledgment: Dr Arindam Biswas, Doctor of Medicine.

Prof. Mrinal Kanti Roy Calcutta National Medical College, Kolkata Chairman, API West Bengal Chapter 